\title{
Predictors of inpatient admission in the setting of anterior lumbar interbody fusion: a Minimally Invasive Spine Study Group (MISSG) investigation
}

\author{
James M. Parrish, MPH, ${ }^{1}$ Nathaniel W. Jenkins, MS, ${ }^{1}$ Michael T. Nolte, MD, ${ }^{1}$ Dustin H. Massel, MD, ${ }^{2}$ \\ Nadia M. Hrynewycz, BS, ${ }^{1}$ Thomas S. Brundage, BS, ${ }^{1}$ Jonathan A. Myers, MD, ${ }^{3}$ Kern Singh, MD, \\ and the Minimally Invasive Spine Study Group (MISSG)
}

${ }^{1}$ Department of Orthopaedic Surgery, Rush University Medical Center, Chicago, Illinois; ${ }^{2}$ Department of Orthopaedics, Miller School of Medicine, University of Miami, Florida; and 'Department of Surgery, Rush University Medical Center, Chicago, Illinois

\begin{abstract}
OBJECTIVE While the anterior lumbar interbody fusion (ALIF) procedure may be amenable to ambulatory surgery, it has been hypothesized that limitations such as the risk of postoperative ileus and vascular complications have hindered transition of this procedure to the outpatient setting. Identification of independent risk factors predisposing patients to inpatient stays of $\geq 24$ hours after ALIF may facilitate better postsurgical outcomes, target modifiable risk factors, and assist in the development of screening tools to transition appropriate patients to the ambulatory surgery center (ASC) setting for this procedure. The purpose of this study was to identify the most relevant risk factors that predispose patients to $\geq 24$-hour admission following ALIF.
\end{abstract}

METHODS A prospectively maintained surgical registry was reviewed for patients undergoing single ALIF between May 2006 and December 2019. Demographics, preoperative diagnosis, perioperative variables, and postoperative complications were evaluated according to their relative risk (RR) elevation for an inpatient stay of $\geq 24$ hours. A Poisson regression model was used to evaluate predictors of inpatient stays of $\geq 24$ hours. Risk factors for inpatient admission of $\geq 24$ hours were identified with a stepwise backward regression model.

RESULTS A total of 111 patients underwent single-level ALIF ( $50.9 \%$ female and $52.6 \%$ male, $\leq 50$ years old). Eleven $(9.5 \%)$ patients were discharged in $<24$ hours and 116 remained admitted for $\geq 24$ hours. The average inpatient stay was $>2$ days ( 53.7 hours). The most common postoperative complications were fever (body temperature $\geq 100.4^{\circ} \mathrm{F} ; \mathrm{n}$ $=4,3.5 \%$ ) and blood transfusions $(n=4,3.5 \%$ ). Bivariate analysis revealed a preoperative diagnosis of retrolisthesis or lateral listhesis to elevate the RR for an inpatient stay of $\geq 24$ hours (RR 1.11, $p=0.001$, both diagnoses). Stepwise multivariate analysis demonstrated significant predictors for inpatient stays of $\geq 24$ hours to be an operation on $\mathrm{L} 4-5$, coexisting degenerative disc disease (DDD) with foraminal stenosis, and herniated nucleus pulposus (RR $1.11,95 \% \mathrm{Cl}$ $1.03-1.20, p=0.009$, all covariates).

CONCLUSIONS This study provides data regarding the incidence of demographic and perioperative characteristics and postoperative complications as they pertain to patients undergoing single-level ALIF. This preliminary investigation identified the most relevant risk factors to be considered before appropriately transitioning ALIF procedures to the ASC. Further studies of preoperative characteristics are needed to elucidate ideal ASC ALIF patients.

https://thejns.org/doi/abs/10.3171/2020.3.SPINE20134

KEYWORDS ALIF; ambulatory surgery center; anterior lumbar interbody fusion; complication; inpatient; morbidity; outpatient; spine

A NTERIOR lumbar interbody fusion (ALIF) procedures have become increasingly prevalent due to a combination of advantages afforded by the procedure itself ${ }^{1-5}$ and because cases indicating elective spinal fusion as an effective treatment have increased more than $60 \%$ over the past decade. ${ }^{6}$ Lumbar interbody fusion remains an efficacious surgical treatment that produces reasonable clinical and radiological outcomes for spinal degenerative pathologies that become symptomatic. Lumbar degenerative spine disease (DSD) causes significant

ABBREVIATIONS ALIF = anterior lumbar interbody fusion; $\mathrm{ASA}=$ American Society of Anesthesiologists; $\mathrm{ASC}=$ ambulatory surgery center; $\mathrm{CCl}=\mathrm{Charlson}$ Comorbidity Index; DDD = degenerative disc disease; DSD = degenerative spine disease; EBL = estimated blood loss; LLIF = lateral lumbar interbody fusion; PLIF = posterior lumbar interbody fusion; TLIF = transforaminal lumbar interbody fusion; VAS = visual analog scale.

SUBMITTED January 29, 2020. ACCEPTED March 18, 2020.

INCLUDE WHEN CITING Published online May 22, 2020; DOI: 10.3171/2020.3.SPINE20134. 
worldwide disability and is associated with numerous clinical symptoms, such as extremity pain and low-back pain.? Underlying pathologies for which lumbar fusion procedures are indicated include degenerative disc disease (DDD), foraminal stenosis, and spondylolisthesis. ${ }^{8}$ There are multiple techniques and approaches that can be used to accomplish spinal fusion. In response to a complex multifactorial exchange between medical, practical, and socioeconomic factors, the prevalence of outpatient spine surgery has also increased within the past 2 decades. Hence, the most attractive procedures to transition to the outpatient setting are those that can accomplish surgical goals while facilitating discharge within $<24$ hours.

Posterior approaches, such as minimally invasive transforaminal lumbar interbody fusions (TLIF), represent a significant achievement in fusion surgery, because they offer many benefits afforded by open procedures and can be performed within the outpatient environment. Although posterior approaches have numerous advantages, they also have been observed to result in higher rates of paravertebral musculature injury, sagittal imbalance, and pseudarthrosis, and greater overall morbidity. Within the past 2 decades, the use of ALIF has increased at a rate disproportionate to that of the aging population. ${ }^{9}$ Much of the increase in ALIF prevalence has been related to its use as an alternative to other approaches associated with higher morbidity, along with the increased access to MRI and new cage designs. ${ }^{9-11}$

The ALIF surgical procedure also permits efficient discectomy to target discogenic back pain and incorporates favorable geometry that allows for the angulated placement of lordotic stabilizing devices, increased bone graft area, high fusion rates, and enhanced overall visualization. ${ }^{12,13}$ Unfortunately, ALIF is contraindicated in several specific patient groups, including patients who have unfavorable abdominal or vascular anatomy or pathologies. ${ }^{12}$ Other difficulties with the ALIF procedures are related to complexities involved in attaining retroperitoneal access. These occur most often at the more caudal levels because the aortic bifurcation and its associated vasculature require extensive distraction and manipulation. Other complications associated with the procedure include adjacent segment degeneration, subsidence, and retrograde ejaculation. . $^{8,14,15}$

In several investigations it was observed that ALIF can be associated with impaired fusion rates, an outcome that apparently required more instrumentation. The increased potentials for adjacent segment disease and implant failure have been hypothesized to be associated with the greater dissection requirements. ${ }^{11,16,17}$ Compared with posterior lumbar interbody fusion (PLIF), ALIF procedures with either posterior pedicle screw fixation or anterior tension band plating have been observed to deliver nearly equivalent outcomes. ${ }^{17,18}$ Hence, ALIF techniques have been developed as "standalone" methods that use little instrumentation other than threaded or intracorporeal screws. ${ }^{19}$ These newer techniques address the limitations of tapered or threaded cages while exhibiting stable biomechanical properties and favorable clinical outcomes. ${ }^{16,20}$

At present, the spine literature is supportive of ALIF, with reports of disability and pain reductions and improved outcomes. Although enhanced disc height restoration and better rates of fusion have been reported, the supporting data are largely preliminary. Furthermore, ALIF is continuing to evolve, with techniques such as the endoscopic ALIF and the "mini ALIF." These procedures could potentially be performed in the outpatient setting, though few data supporting this option have been produced. It is hypothesized that possible barriers to adapting ALIF to the outpatient setting include the requirement for postoperative observation to detect possible ileus or vascular complications. Identification of independent risk factors that predispose patients to inpatient stays of $\geq 24$ hours in the setting of ALIF may facilitate better postsurgical outcomes and targeting of modifiable risk factors and assist in the development of screening tools to identify patients for whom the ALIF procedure may be transitioned to the ambulatory surgery center (ASC) setting. The purpose of this study was to identify the most relevant risk factors that predispose patients to $\geq 24$-hour admission following ALIF.

\section{Methods \\ Patient Population}

After institutional review board approval was obtained (ORA 14051301), a prospectively maintained surgical registry was retrospectively reviewed for patients undergoing single-level ALIF between May 2006 and December 2019. Inclusion criteria were patients who had undergone elective, primary, single- or multilevel ALIFs for degenerative spine pathologies. Patients were excluded if they had undergone surgery due to trauma, infection, or metastasis.

\section{Data Collection}

Recorded variables included the following baseline demographic characteristics: age, sex, BMI, smoking status, American Society of Anesthesiologists (ASA) score, Charlson Comorbidity Index (CCI) score, spinal pathology diagnosis, preoperative visual analog scale (VAS) pain scores, and preoperative diagnosis of hypertension or diabetes. Spinal pathology was determined during the preoperative visit through the evaluation of radiographic imaging. Perioperative variables included operative duration (from skin incision to closure), estimated blood loss (EBL), number of operative levels, location of operative level, and duration of postoperative inpatient stay. All postoperative complications that occurred during the patient's hospital stay were recorded.

\section{Statistical Analysis}

Stata 16.0 (StataCorp) was used to perform all calculations and statistical analyses. Descriptive statistics, including proportions, means, and ranges, were reported for baseline demographics and perioperative variables. Patients may have been diagnosed with more than one medical or spinal pathology. A bivariate Poisson regression model with robust error variance was used to evaluate predictors of inpatient stays of $\geq 24$ hours. Demographics, preoperative diagnosis, perioperative variables, and postoperative complications were evaluated according to how much they elevated the relative risk of an inpatient 
TABLE 1. Patient demographic and perioperative characteristics

\begin{tabular}{|c|c|c|}
\hline & No. of Patients (\%) & Mean (range) \\
\hline Total no. of patients & 116 & \\
\hline Age, yrs & & $59.7(25.9-71.7)$ \\
\hline$\leq 50$ & $61(52.6 \%)$ & \\
\hline$>50$ & $55(47.4 \%)$ & \\
\hline \multicolumn{3}{|l|}{ Sex } \\
\hline Male & $57(49.1 \%)$ & \\
\hline Female & $59(50.9 \%)$ & \\
\hline $\mathrm{BMI}, \mathrm{kg} / \mathrm{m}^{2}$ & & $30.4(18.9-49.9)$ \\
\hline$<30$ & $64(55.2 \%)$ & \\
\hline$\geq 30$ & $52(44.8 \%)$ & \\
\hline \multicolumn{3}{|l|}{ Smoking status } \\
\hline Nonsmoker & $90(77.6 \%)$ & \\
\hline Smoker & $26(22.4 \%)$ & \\
\hline Postop observation, hrs & & $53.7(8.7-430.1)$ \\
\hline$<24$ & $11(9.5 \%)$ & \\
\hline$\geq 24$ & $105(90.5 \%)$ & \\
\hline ASA score & & $2.0(1-4)$ \\
\hline$\leq 2$ & $93(80.2 \%)$ & \\
\hline$>2$ & $23(19.8 \%)$ & \\
\hline $\mathrm{CCl}$ score & & $1.0(0-7)$ \\
\hline$<1$ & $38(38.4 \%)$ & \\
\hline$\geq 1$ & $61(61.6 \%)$ & \\
\hline \multicolumn{3}{|l|}{ Hypertension } \\
\hline Nonhypertensive & $84(72.4 \%)$ & \\
\hline Hypertensive & $32(27.6 \%)$ & \\
\hline \multicolumn{3}{|l|}{ Diabetes } \\
\hline Nondiabetic & $102(87.9 \%)$ & \\
\hline Diabetic & $14(12.1 \%)$ & \\
\hline Preop VAS pain score & & $7.2(1-10)$ \\
\hline$<7$ & $30(30.9 \%)$ & \\
\hline$\geq 7$ & $67(69.1 \%)$ & \\
\hline Op duration, mins & & $158.4(55-562)$ \\
\hline$\leq 105$ & $34(29.3 \%)$ & \\
\hline$>105$ & $82(70.7 \%)$ & \\
\hline $\mathrm{EBL}, \mathrm{mL}$ & & $105.0(25-2500)$ \\
\hline$\leq 50$ & $61(52.6 \%)$ & \\
\hline$>50$ & $55(47.4 \%)$ & \\
\hline
\end{tabular}

stay $\geq 24$ hours. A stepwise backward Poisson regression model with robust error variance was then used to identify independent risk factors for an inpatient admission of $\geq 24$ hours. Patients with DDD and any additional spinal diagnosis were analyzed as unique diagnosis groups reflecting coexisting diagnoses (e.g., those with DDD alone, those with DDD and foraminal stenosis, etc.) in the regression analysis. Statistical significance was set at $\mathrm{p}<0.05$.

\section{Surgical Technique}

Patients were placed on a flat table in the supine po-
TABLE 2. Rates of preoperative spinal pathologies

\begin{tabular}{lc}
\hline \multicolumn{1}{c}{ Pathology } & No. of Patients (\%) \\
\hline DDD & $78(67.2 \%)$ \\
\hline Degenerative spondylolisthesis & $73(63.0 \%)$ \\
\hline Isthmic spondylolisthesis & $53(45.7 \%)$ \\
\hline Foraminal stenosis & $49(42.2 \%)$ \\
\hline Retrolisthesis & $7(6.0 \%)$ \\
\hline Herniated nucleus pulposus & $7(6.0 \%)$ \\
\hline Lateral listhesis & $1(0.9 \%)$ \\
\hline
\end{tabular}

sition. The appropriate disc level(s) was (were) preoperatively localized via fluoroscopy and an anterior paramedian approach was performed. An annulotomy was then performed at the disc space. The vertebral endplates were then defined with a Cobb elevator, and a pituitary rongeur was utilized to remove the remaining disc fragments. Sequential trial implants were placed for sizing, and the preparation of the final interbody was completed with allograft. Screw placement was accomplished within the interbody screw holds. One screw was positioned into the superior and 1 screw was positioned into the inferior vertebral body.

\section{Results}

\section{Demographic Characteristics}

Our cohort included a total of 111 patients who underwent a single-level ALIF procedure (50.9\% female, $52.6 \%$ $\leq 50$ years old, mean age 59.7 years [range 25.9-71.7 years], Table 1). The majority of patients had a BMI $<30$ $\mathrm{kg} / \mathrm{m}^{2}(55.2 \%)$ and were nonsmokers (77.6\%). A greater proportion of patients had an ASA score of $\leq 2(80.2 \%)$, a CCI score of $\geq 1(61.6 \%)$, and were nonhypertensive (72.4\%) and nondiabetic (87.9\%). The mean preoperative VAS pain score was 7, with $69.1 \%$ of patients scoring $\geq 7$. The 3 most common spinal pathologies were DDD (67.2\%), degenerative spondylolisthesis (63.0\%), and isthmic spondylolisthesis (45.7\%, Table 2).

\section{Perioperative Characteristics}

The mean operative time was 158.4 minutes, with the majority of procedures $(70.7 \%)$ taking longer than 105 minutes (Table 1). Eleven $(9.5 \%)$ patients were discharged in $<24$ hours and $105(90.5 \%)$ remained admitted for $\geq$ 24 hours. The average inpatient stay was $>2$ days. There was 1 patient outlier for length of stay, with a duration of 17 days.

\section{Complications}

The most common postoperative complications were fever (temperature $\geq 100.4^{\circ} \mathrm{F}, \mathrm{n}=4,3.5 \%$, Table 3) and blood transfusions $(n=4,3.5 \%)$. Our criteria for fever included a temperature $\geq 100.4^{\circ} \mathrm{F}$ and undergoing at least 1 part of a fever workup (e.g., chest radiograph, urinalysis, or cultures). Infectious pathologies were not associated with any fever case. Other postoperative complications 
TABLE 3. Rates of postoperative complications

\begin{tabular}{lc}
\hline \multicolumn{1}{c}{ Complication } & No. of Patients (\%) \\
\hline Fever & $4(3.5 \%)$ \\
\hline Blood transfusion & $4(3.5 \%)$ \\
\hline Urinary retention requiring catheterization & $1(0.8 \%)$ \\
\hline Cardiac arrhythmia & $1(0.8 \%)$ \\
\hline Vascular complication & $1(0.8 \%)$ \\
\hline Ileus & $0(0.0 \%)$ \\
\hline Urinary tract infection & $0(0.0 \%)$ \\
\hline Acute renal failure & $0(0.0 \%)$ \\
\hline Aspiration & $0(0.0 \%)$ \\
\hline Deep vein thrombosis & $0(0.0 \%)$ \\
\hline Aspiration & $0(0.0 \%)$ \\
\hline Pneumothorax & $0(0.0 \%)$ \\
\hline Pneumonia & $0(0.0 \%)$ \\
\hline Altered mental status & $0(0.0 \%)$ \\
\hline Durotomy & $0(0.0 \%)$ \\
\hline Surgical site infection & $0(0.0 \%)$ \\
\hline
\end{tabular}

occurred in 1 patient each. These complications included cardiac arrhythmia, vascular complications, and urinary retention. The 1 patient diagnosed with postoperative urinary retention required placement of an indwelling catheter. It is also important to point out that this patient had a history of receiving treatment for benign prostatic hyperplasia (BPH). The 1 patient with a vascular complication was also the outlier for length of stay, with a 17-day admission. This patient's vascular complication occurred due to a plaque disruption and thrombosis of the left common and external iliac arteries and required vascular surgery, including a thrombectomy, endarterectomy, pericardial patch angioplasty, and covered stent placement.

\section{Predictors of Extended Inpatient Stay}

Assessment with bivariate analysis indicated that the preoperative spinal pathologies retrolisthesis (RR 1.11, p $=0.001$, Table 4) and lateral listhesis $(\mathrm{RR} 1.11, \mathrm{p}=0.001)$ had the largest RR elevations associated with an inpatient stay of $\geq 24$ hours. Stepwise multivariate analysis revealed the following conditions to be the most significant predictors for an inpatient stay of $\geq 24$ hours: operative level L4-5, coexisting degenerative disc disease with foraminal stenosis, and herniated nucleus pulposus (Table 5, RR 1.11, 95\% CI 1.03-1.20, all $\mathrm{p}=0.009$ ).

\section{Discussion}

Using the anterior approach for an interbody fusion has numerous advantages, including better operative visualization and increased ability to correct lumbar lordosis and sagittal parameters, as well as decreased manipulation of posterior nerves. The invasive nature of gaining anterior access has, in some cases, been observed to increase the risk of poor postoperative outcomes compared to those for posterior fusion procedures. While multiple studies have attempted to identify the risk factors for postoperative complications in the setting of ALIF, to our knowledge, none have assessed which complications are most associated with inpatient admissions of $\geq 24$ hours.

\section{Pre- and Perioperative Risk Factors for ALIF Postoperative Complications}

The risk factors that are most associated with poor ALIF outcomes vary by study design. Because this is, to our knowledge, the first study to evaluate risk factors associated with $\mathrm{a} \geq 24$-hour inpatient stay, the potential to make direct comparisons is limited. Our full patient cohort had considerable variation in discharge times (mean 53.7, range 8.7-430.1 hours). We selected hours as the unit of measure for time duration from surgery completion until hospital discharge. The ambulatory surgical setting is limited to a postoperative observation time of $<24$ hours. Measuring hours instead of postoperative days assisted in providing meaningful accuracy in this context. Additionally, measuring length of admission by postoperative days can be misleading. For example, patient A could be admitted after surgery at $7 \mathrm{AM}$, and be discharged on postoperative day (POD) 1, at 10 PM. Patient B might be admitted at 4 PM and could be discharged on POD 1 at 7 AM. In these cases, although both patients were discharged on POD 1, patient A has an admission time of 39 hours, while patient B has an admission time of 16 hours. To our knowledge, analysis focused on a 24-hour discharge cutoff is not reported in other ALIF investigations. However, at least 3 studies have elaborated preoperative risk factors as predictors of complications following ALIF.

The studies that have elaborated on risk factors were predominantly derived from analyses of the American College of Surgeons (ACS) National Surgical Quality Improvement Project (NSQIP) database. ${ }^{21,22}$ Following multivariate regression, Phan et al. found statistically significant predictors of complications following ALIF to be obesity (BMI $\left.>40.0 \mathrm{~kg} / \mathrm{m}^{2}, \mathrm{p}=0.002\right)$, alcohol use ( $>2$ drinks/day in 2 weeks before admission, $p=0.004$ ), and diabetes $(\mathrm{p}=0.001) .{ }^{22}$ In their analysis of 2042 patients, Garcia et al. found that their multivariable logistic analysis revealed that only pneumonia diagnosed after surgery $(\mathrm{p}<0.001)$ and superficial wound infections $(\mathrm{p}<0.001)$ were predictive of complications that required readmission within 30 days. ${ }^{21}$ Finally, Choy et al. observed that according to multivariable logistic regression analysis, variables that contributed to surgical complications following ALIF included diabetes $(\mathrm{p}=0.009)$, corticosteroid use for chronic conditions $(\mathrm{p}=0.003)$, transfusion ( $>4$ units packed red blood cells, $p=0.016)$, long operating times ( $p$ $<0.001)$, preoperative anemia $(\mathrm{p}<0.001)$, male sex $(\mathrm{p}=$ $0.012)$, smoking $(\mathrm{p}=0.013),>10 \%$ body weight loss $(>6$ months preoperatively, $\mathrm{p}=0.049$ ), and ASA classifications of 3 or greater $(\mathrm{p}<0.001){ }^{23}$

At least one previously reported study focused on the influence of a single risk factor. In their assessment of the influence of obesity on complications and clinical and radiographic outcomes after ALIF, Phan et al. found no differences in patient-reported outcomes or complication rates among normal, overweight, and obese individuals. ${ }^{24}$ However, Phan et al. did observe significantly different an- 
TABLE 4. Bivariate analysis of demographic data, preoperative diagnoses, and postoperative complications

\begin{tabular}{|c|c|c|c|c|}
\hline & Inpatient Stay $\geq 24 \mathrm{Hrs}$ & $\mathrm{RR}$ & $95 \% \mathrm{Cl}$ & $\mathrm{p}$ Value \\
\hline \multicolumn{5}{|l|}{ Age, yrs } \\
\hline$\leq 5$ & $52.6 \%$ & Ref & & \\
\hline$>50$ & $47.4 \%$ & 1.01 & $0.89-1.13$ & 0.891 \\
\hline \multicolumn{5}{|l|}{ Sex } \\
\hline Male & $49.1 \%$ & 0.91 & $0.81-1.03$ & 0.130 \\
\hline Female & $50.9 \%$ & Ref & & \\
\hline \multicolumn{5}{|l|}{$\mathrm{BMI}, \mathrm{kg} / \mathrm{m}^{2}$} \\
\hline$<30$ & $55.2 \%$ & Ref & & \\
\hline$\geq 30$ & $44.8 \%$ & 1.1 & $0.96-1.21$ & 0.206 \\
\hline \multicolumn{5}{|l|}{ Smoking status } \\
\hline Nonsmoker & $77.6 \%$ & Ref & & \\
\hline Smoker & $22.4 \%$ & 1.0 & $0.90-1.17$ & 0.705 \\
\hline \multicolumn{5}{|l|}{ ASA score } \\
\hline$\leq 2$ & $80.1 \%$ & Ref & & \\
\hline$>2$ & $19.8 \%$ & 1.07 & $0.95-1.20$ & 0.228 \\
\hline \multicolumn{5}{|l|}{$\mathrm{CCl}$ score } \\
\hline$<1$ & $67.2 \%$ & Ref & & \\
\hline$\geq 1$ & $32.8 \%$ & 1.02 & $0.89-1.16$ & 0.795 \\
\hline \multicolumn{5}{|l|}{ Hypertension } \\
\hline Nonhypertensive & $72.4 \%$ & Ref & & \\
\hline Hypertensive & $27.6 \%$ & 1.05 & $0.93-1.18$ & 0.412 \\
\hline \multicolumn{5}{|l|}{ Diabetes status } \\
\hline Nondiabetic & $87.9 \%$ & Ref & & \\
\hline Diabetic & $12.1 \%$ & 1.03 & $0.88-1.21$ & 0.721 \\
\hline \multicolumn{5}{|l|}{ Preop VAS pain score } \\
\hline$<7$ & $69.1 \%$ & Ref & & \\
\hline$\geq 7$ & $30.9 \%$ & 1.00 & $0.86-1.15$ & 0.946 \\
\hline \multicolumn{5}{|l|}{ Spinal pathology } \\
\hline DDD & $67.2 \%$ & 1.02 & $0.89-1.16$ & 0.795 \\
\hline Degenerative spondylolisthesis & $63.9 \%$ & 1.04 & $0.92-1.17$ & 0.527 \\
\hline Isthmic spondylolisthesis & $45.7 \%$ & 1.00 & $0.89-1.13$ & 0.987 \\
\hline Retrolisthesis & $6.0 \%$ & 1.11 & $1.04-1.18$ & 0.001 \\
\hline Lateral listhesis & $0.9 \%$ & 1.11 & $1.04-1.17$ & 0.001 \\
\hline Foraminal stenosis & $45.7 \%$ & 0.89 & $0.78-1.01$ & 0.076 \\
\hline Herniated nucleus pulposus & $6.0 \%$ & 0.94 & $0.69-1.29$ & 0.713 \\
\hline \multicolumn{5}{|l|}{ Op duration, mins } \\
\hline$\leq 105$ & $29.3 \%$ & Ref & & \\
\hline$>105$ & $70.7 \%$ & 0.99 & $0.87-1.12$ & 0.874 \\
\hline \multicolumn{5}{|l|}{ Op level } \\
\hline L3-4 & $3.5 \%$ & 0.54 & $0.20-1.46$ & 0.226 \\
\hline L4-5 & $14.7 \%$ & 1.05 & $0.91-1.20$ & 0.510 \\
\hline L5-S1 & $81.9 \%$ & 1.07 & $0.89-1.28$ & 0.485 \\
\hline
\end{tabular}

Values are presented as percentages of patients unless otherwise indicated. Boldface indicates statistical significance; $p$ values calculated using bivariate Poisson regression with robust error variance. 
TABLE 5. Multivariate analysis for independent risk factors for $\geq$ 24-hour inpatient stay

\begin{tabular}{lccc}
\hline & RR & $95 \% \mathrm{Cl}$ & $\mathrm{p}$ Value \\
\hline L4-5 op level & 1.11 & $1.03-1.20$ & $\mathbf{0 . 0 0 9}$ \\
\hline Coexisting DDD \& foraminal stenosis & 1.11 & $1.03-1.20$ & $\mathbf{0 . 0 0 9}$ \\
\hline Herniated nucleus pulposus & 1.11 & $1.03-1.20$ & $\mathbf{0 . 0 0 9}$ \\
\hline
\end{tabular}

Boldface indicates statistical significance; $p$ values calculated using backward stepwise Poisson regression with robust error variance.

terior disc heights at the final follow-up between normal weight $(14.44 \mathrm{~mm})$, overweight $(17.05 \mathrm{~mm})$, and obese patients $(11.33 \mathrm{~mm}, \mathrm{p}=0.004) .{ }^{24} \mathrm{In}$ addition, the proportion of patients achieving successful fusion was significantly different between normal weight $(88.2 \%)$, overweight $(76 \%)$, and obese patients $(60 \%, \mathrm{p}=0.014) .{ }^{24}$ While the aforementioned obesity investigation examined numerous outcomes, our study did not reveal BMI as a statistically significant predictor for our outcome of interest (e.g., inpatient stays $\geq 24$ hours).

In our study, statistically significant preoperative risk factors associated with inpatient stays of $\geq 24$ hours were operations at L4-5, coexisting DDD with foraminal stenosis, and herniated nucleus pulposus (RR $1.11,95 \% \mathrm{CI}$ $1.03-1.20, p=0.009$, all covariates). Our outcome of interest, however, was inpatient stays $\geq 24$ hours in duration, whereas the aforementioned investigations assessed risk factors that contributed to complications that ultimately led to increased readmission rates.

\section{Spinal Pathologies With Associated Complications}

The literature is scarce regarding the possible association of spinal pathologies with postoperative complications following ALIF. During our bivariate risk factor analysis, several spinal pathologies were found to be statistically significant, including retrolisthesis and lateral listhesis $(\mathrm{p}$ $=0.001)$. Other pathologies were significant during subsequent multivariable regression, including coexisting foraminal stenosis with DDD and herniated nucleus pulpo$\operatorname{sus}(p=0.009)$.

While DDD is also among the most common indications for ALIF, 3,26 we observed that patients in our study with coexisting DDD and foraminal stenosis had a slight increase in their chances of a $>24$-hour inpatient stay (RR $1.11, p=0.009)$. DDD, without the presence of foraminal stenosis, can cause chronic mechanical lower-back pain. Mechanical loading to these areas can cause delamination, disc degeneration, and annular posterior fissuring. DDD coupled with foraminal stenosis may be associated with disc bulging and compression as well as narrowing of the foramina. Annular receptors may become sensitized at any point during these changes. ${ }^{27}$ Further degenerative processes that can potentiate pain include neovascularization, nerve demyelination, and Schwann cell neoinnervation. ${ }^{28}$ In consideration of the mechanisms addressing pain associated with this pathology, it could be that patients undergoing ALIF with DDD required $\geq 24$ hours of inpatient observation time due to residual pain. Further subanalyses are necessary to investigate the relationship between DDD and other pathologies with inpatient stays of $\geq 24$ hours.

\section{Complications Associated With Worse ALIF Outcomes}

Although the literature is scarce regarding preoperative risk factors, ALIF literature more often includes reported investigations of the most frequent complications resulting in worse outcomes or higher readmission rates. While our study was based on 111 patients, most ALIF research is supported by individual studies with limited patient sample sizes $(n \leq 100)$ and heterogeneous patient or disease-specific populations. ${ }^{14,29-34}$ Outcomes also vary among individual ALIF studies, systematic reviews, and meta-analysis studies. For example, individual investigations often focus on complications in general, larger data studies tend to focus on complications as they relate to readmission, and systematic reviews and meta-analyses attempt to address ALIF feasibility concerns.

\section{Fever}

Early ALIF literature includes reports of fever in association with infections hypothesized to arise from peritoneal perforations in high-risk patients. ${ }^{35}$ While recent ALIF literature includes reports of systemic complications, including sepsis, pneumonia, or other infectious etiologies, ${ }^{22}$ mention of transiently elevated postoperative temperature in these reports is scarce. In the present study, although 4 patients had an elevated temperature, none of their workups resulted in a fever-associated diagnosis prior to discharge. In order to be considered to have a postoperative fever, patients were screened for having any postoperative temperature reading indicative of fever $\left(\geq 100.4^{\circ} \mathrm{F}\right)$ and at least 1 diagnostic fever workup test. Postoperative, inpatient, and outpatient notes were reviewed for any one of the following components: blood culture, chest CT, chest radiograph, sputum culture, urinalysis, urine culture, or venous duplex ultrasound. Patients were observed until the transient elevation in temperature dissipated or until the workup revealed no identifiable underlying cause. All 4 of the patients with fever were discharged home uneventfully.

\section{Blood Transfusion}

One of the most typical concerns with exposure of the anterior spine is blood loss due to retraction of the internal viscera and blood vessels. Reports in the literature are divided regarding the frequency of blood transfusions. We observed blood transfusions to have occurred in 4 (3.5\%) cases, though the rates reported in the ALIF literature are variable, ranging from $0^{21}$ to $18 \% .{ }^{22}$ While rates as high as $14 \%-18 \%$ have been reported in some studies, blood transfusion has not been observed to be a statistically significant predictor for 30-day readmission $\mathrm{s}^{22}$ or discharge to inpatient care facilities. ${ }^{25}$ Other investigators have examined blood transfusions in this setting and determined that transfusions were not associated with any complication differences between ALIF/direct lateral interbody fusions and PLIF/TLIF procedures. ${ }^{36}$

\section{Vascular Complications}

The nature of the anterior approach exposes vulnerable 
vasculature, such as the iliac artery and veins, which frequently necessitates the assistance of an access surgeon to safely navigate down to the disc space. In our study, 1 patient experienced vascular complications, which resulted in thrombosis of the left common and external iliac arteries, resulting in a 17-day postoperative stay. In a study of 1315 patients undergoing ALIFs, Brau et al. reported a vascular injury rate of $1.9 \%$, of which $76 \%$ of injuries were venous in nature. ${ }^{37}$ Quraishi et al. observed a vascular injury rate of $4.6 \%$ in 304 consecutive ALIFs, ${ }^{2}$ and Hamdan et al. reported a rate of $1.9 \%$ for major vascular injuries in 480 ALIFs. ${ }^{38}$ The reported overall vascular injury rate is $3 \%,{ }^{39}$ which is slightly more than the rate observed in our study (2.2\%).

\section{Comparison to the Lateral Transpsoas Approach}

Indications for the lateral transpsoas approach used in lateral lumbar interbody fusions (LLIF) overlap with those for ALIFs, albeit with a different approach-related complication profile. Investigations of leg weakness or sensory dysesthesia from LLIFs have identified substantially varied rates, ranging from $12.5 \%$ to $75 \% .39,40$ This variation could, in part, be related to variations in the proximity to the lumbar plexus and disruption of the psoas muscle. The lateral positioning required for the LLIF approach allows gravity to move the abdominal viscera downward and away from the spine. This positioning can reduce the need for retraction of abdominal viscera. ${ }^{41} \mathrm{~A}$ study by Chin et al. evaluated the outcomes of LLIFs in the ASC setting and found an overall complication rate of $7.0 \%$ compared to that for inpatient LLIFs at $20 \% .42$ The most common complication for LLIFs performed in both inpatient and ASC settings was dermatomal numbness. ${ }^{42}$ The patient selection criteria for ASC LLIFs used by Chin et al. included a maximum BMI of $42 \mathrm{~kg} / \mathrm{m}^{2}$, single-level fusions, and the ability to perform a procedure that avoids involving L5$\mathrm{S} 1{ }^{42}$ The lateral transpsoas approach is predominantly not a viable option for L5-S1 procedures due to the obstructing iliac crests. ${ }^{39,41}$

Interestingly, for ALIFs, an operation at L5-S1 is often more straightforward because it provides the surgeon with the largest working space, requires less bowel manipulation than ALIFs at other levels, and does not require iliolumbar vein ligation. When performing an ALIF on more superior levels (e.g., L4-5, L3-4), however, more extensive retraction of abdominal viscera is often required to provide adequate visualization..$^{39}$ The L4-5 level also introduces greater vascular risk given the bifurcation of the aorta into the iliac vessels. ${ }^{41}$ Persistent postoperative ileus is a complication that should be considered following ALIF due to the prolonged retraction of intestinal viscera. The rate of ileus following ALIF is relatively low, with reported rates ranging from $0.6 \%$ to $17.3 \% .^{43-45}$

\section{Study Limitations}

This study has limitations that should be considered when evaluating our results. The retrospective nature of this study may lead to observer bias. Unblinded investigators can be more likely to observe results they expect. This topic could more rigorously be addressed with a blinded prospective study design in order to investigate risk factors that contribute to an extended hospital length of stay following ALIFs. Secondly, a number of comparison studies reported 30-day readmission rates that were attributalbe to slower-evolving complications. Our study was limited to only those complications that patients experienced while in the hospital. Additionally, preoperative data that might be derived from patient-reported outcome measures (PROM) for mental health, disability, or preoperative narcotic usage were limited. As a result, we were unable to include PROM scores as variables in our analysis. It would be beneficial for future prospective investigations to evaluate the influence of multiple realms of health (as reflected by PROM scores) on the lengths of inpatient stays following ALIF.

\section{Conclusions}

In summary, ALIF has numerous benefits and can be performed safely among the correct patient population. In this study, we assessed baseline demographics, perioperative characteristics, and complications in the postoperative setting in order to identify which patients were most likely to require inpatient admissions of $\geq 24$ hours in duration. Preoperative factors that were observed to favor inpatient admissions of $\geq 24$ hours included operations at L4-5, coexisting DDD with foraminal stenosis, and herniated nucleus pulposus. Although this study serves as an initial analysis to discern the most relevant factors that warrant consideration when moving ALIF procedures to the ASC, further studies are needed to address which patient characteristics are most likely to facilitate a post-ALIF discharge in $<24$ hours.

\section{Acknowledgments}

Funding for the Minimally Invasive Spine Study Group, a nonprofit organization through which this study was conducted, was provided through research grants from Stryker K2M, Inc., and individual donations.

\section{References}

1. Ikard RW. Methods and complications of anterior exposure of the thoracic and lumbar spine. Arch Surg. 2006;141(10):1025-1034.

2. Quraishi NA, Konig M, Booker SJ, et al. Access related complications in anterior lumbar surgery performed by spinal surgeons. Eur Spine J. 2013;22(suppl 1):S16-S20.

3. Mobbs RJ, Loganathan A, Yeung V, Rao PJ. Indications for anterior lumbar interbody fusion. Orthop Surg. 2013;5(3):153-163.

4. Chen D, Fay LA, Lok J, et al. Increasing neuroforaminal volume by anterior interbody distraction in degenerative lumbar spine. Spine (Phila Pa 1976). 1995;20(1):74-79.

5. Dennis S, Watkins R, Landaker S, et al. Comparison of disc space heights after anterior lumbar interbody fusion. Spine (Phila Pa 1976). 1989;14(8):876-878.

6. Martin BI, Mirza SK, Spina N, et al. Trends in lumbar fusion procedure rates and associated hospital costs for degenerative spinal diseases in the United States, 2004 to 2015. Spine (Phila Pa 1976). 2019;44(5):369-376.

7. Ravindra VM, Senglaub SS, Rattani A, et al. Degenerative lumbar spine disease: estimating global incidence and worldwide volume. Global Spine J. 2018;8(8):784-794.

8. Hoff EK, Strube P, Pumberger M, et al. ALIF and total disc 
replacement versus 2-level circumferential fusion with TLIF: a prospective, randomized, clinical and radiological trial. Eur Spine J. 2016;25(5):1558-1566.

9. Harris IA, Dao ATT. Trends of spinal fusion surgery in Australia: 1997 to 2006. ANZ J Surg. 2009;79(11):783-788.

10. Rajaee SS, Bae HW, Kanim LEA, Delamarter RB. Spinal fusion in the United States: analysis of trends from 1998 to 2008. Spine (Phila Pa 1976). 2012;37(1):67-76.

11, Sasso RC, Reichard AK, Shah S. Anterior Lumbar Interbody Fusion. Surgical Management of Low Back Pain. 2nd ed. Thieme; 2008.

12. Mobbs RJ, Phan K, Malham G, et al. Lumbar interbody fusion: techniques, indications and comparison of interbody fusion options including PLIF, TLIF, MI-TLIF, OLIF/ATP, LLIF and ALIF. J Spine Surg. 2015;1(1):2-18.

13. Mobbs RJ, Lennox A, Ho Y-T, et al. L5/S1 anterior lumbar interbody fusion technique. J Spine Surg. 2017;3(3):429-432.

14. Udby PM, Bech-Azeddine R. Clinical outcome of standalone ALIF compared to posterior instrumentation for degenerative disc disease: a pilot study and a literature review. Clin Neurol Neurosurg. 2015;133:64-69.

15. Burkus JK, Dryer RF, Peloza JH. Retrograde ejaculation following single-level anterior lumbar surgery with or without recombinant human bone morphogenetic protein- 2 in 5 randomized controlled trials: clinical article. J Neurosurg Spine. 2013;18(2):112-121.

16. Chen S-H, Chiang M-C, Lin J-F, et al. Biomechanical comparison of three stand-alone lumbar cages-a three-dimensional finite element analysis. BMC Musculoskelet Disord. 2013;14(1):281.

17. Aryan HE, Lu DC, Acosta FL Jr, Ames CP. Stand-alone anterior lumbar discectomy and fusion with plate: initial experience. Surg Neurol. 2007;68(1):7-13.

18. Kim J-S, Kang B-U, Lee S-H, et al. Mini-transforaminal lumbar interbody fusion versus anterior lumbar interbody fusion augmented by percutaneous pedicle screw fixation: a comparison of surgical outcomes in adult low-grade isthmic spondylolisthesis. J Spinal Disord Tech. 2009;22(2):114-121.

19. Phan K, Mobbs RJ. Evolution of design of interbody cages for anterior lumbar interbody fusion. Orthop Surg. 2016;8(3):270-277.

20. Behrbalk E, Uri O, Parks RM, et al. Fusion and subsidence rate of stand alone anterior lumbar interbody fusion using PEEK cage with recombinant human bone morphogenetic protein-2. Eur Spine J. 2013;22(12):2869-2875.

21. Garcia RM, Choy W, DiDomenico JD, et al. Thirty-day readmission rate and risk factors for patients undergoing single level elective anterior lumbar interbody fusion (ALIF). J Clin Neurosci. 2016;32:104-108.

22. Phan K, Lee NJ, Kothari P, et al. Risk factors for readmissions following anterior lumbar interbody fusion. Spine (Phila Pa 1976). 2018;43(5):364-369.

23. Choy W, Barrington N, Garcia RM, et al. Risk factors for medical and surgical complications following single-level ALIF. Global Spine J. 2017;7(2):141-147.

24. Phan K, Rogers P, Rao PJ, Mobbs RJ. Influence of obesity on complications, clinical outcome, and subsidence after anterior lumbar interbody fusion (ALIF): prospective observational study. World Neurosurg. 2017;107:334-341.

25. Malik AT, Kim J, Yu E, Khan SN. Discharge to inpatient care facility after anterior lumbar interbody fusion: incidence, predictors, and postdischarge outcomes. World Neurosurg. 2019;122:e584-e590.

26. Giang G, Mobbs R, Phan S, et al. Evaluating outcomes of stand-alone anterior lumbar interbody fusion: a systematic review. World Neurosurg. 2017;104:259-271.

27. Osti OL, Vernon-Roberts B, Fraser RD: Anulus tears and intervertebral disc degeneration: an experimental study using an animal model. Spine (Phila Pa 1976). 1990;15(8):762-767.
28. Andersson GBJ, Mekhail NA, Block JE. Treatment of intractable discogenic low back pain. A systematic review of spinal fusion and intradiscal electrothermal therapy (IDET). Pain Physician. 2006;9(3):237-248.

29. Rao PJ, Loganathan A, Yeung V, Mobbs RJ. Outcomes of anterior lumbar interbody fusion surgery based on indication: a prospective study. Neurosurgery. 2015;76(1):7-24.

30. Siepe CJ, Stosch-Wiechert K, Heider F, et al. Anterior standalone fusion revisited: a prospective clinical, X-ray and CT investigation. Eur Spine J. 2015;24(4):838-851.

31. Allain J, Delecrin J, Beaurain J, et al. Stand-alone ALIF with integrated intracorporeal anchoring plates in the treatment of degenerative lumbar disc disease: a prospective study on 65 cases. Eur Spine J. 2014;23(10):2136-2143.

32. Sato J, Ohtori S, Orita S, et al. Radiographic evaluation of indirect decompression of mini-open anterior retroperitoneal lumbar interbody fusion: oblique lateral interbody fusion for degenerated lumbar spondylolisthesis. Eur Spine J. 2017;26(3):671-678.

33. Verbruggen D, Tampere T, Uyttendaele D, et al. Long-term follow-up of the anterior lumbar interbody fusion procedure. Acta Orthop Belg. 2015;81(3):546-552.

34. Mamuti M, Fan S, Liu J, et al. Mini-open anterior lumbar interbody fusion for recurrent lumbar disc herniation following posterior instrumentation. Spine (Phila Pa 1976). 2016;41(18):E1104-E1114.

35. Watkins R. Anterior lumbar interbody fusion surgical complications. Clin Orthop Relat Res. 1992;(284):47-53.

36. Shillingford JN, Laratta JL, Lombardi JM, et al. Complications following single-level interbody fusion procedures: an ACS-NSQIP study. J Spine Surg. 2018;4(1):17-27.

37. Brau SA, Delamarter RB, Schiffman ML, et al. Vascular injury during anterior lumbar surgery. Spine J. 2004;4(4):409412.

38. Hamdan AD, Malek JY, Schermerhorn ML, et al. Vascular injury during anterior exposure of the spine. J Vasc Surg. 2008;48(3):650-654.

39. Xu DS, Walker CT, Godzik J, et al. Minimally invasive anterior, lateral, and oblique lumbar interbody fusion: a literature review. Ann Transl Med. 2018;6(6):104.

40. Mundis GM, Akbarnia BA, Phillips FM. Adult deformity correction through minimally invasive lateral approach techniques. Spine (Phila Pa 1976). 2010;35(26)(suppl):S312-S321.

41. Winder MJ, Gambhir S. Comparison of ALIF vs. XLIF for L4/5 interbody fusion: pros, cons, and literature review. $J$ Spine Surg. 2016;2(1):2-8.

42. Chin KR, Pencle FJR, Coombs AV, et al. Lateral lumbar interbody fusion in ambulatory surgery centers: patient selection and outcome measures compared with an inhospital cohort. Spine (Phila Pa 1976). 2016;41(8):686-692.

43. Mayer HM, Wiechert K, Microsurgical anterior approaches to the lumbar spine for interbody fusion and total disc replacement. Neurosurgery. 2002;51(5)(suppl):S159-S165.

44. Chiriano J, Abou-Zamzam AM Jr, Urayeneza O, et al. The role of the vascular surgeon in anterior retroperitoneal spine exposure: preservation of open surgical training. J Vasc Surg. 2009;50(1):148-151.

45. Asha MJ, Choksey MS, Shad A, et al. The role of the vascular surgeon in anterior lumbar spine surgery. Br J Neurosurg. 2012;26(4):499-503.

\section{Disclosures}

Dr. Singh reports receiving royalties from Zimmer Biomet, Stryker, RTI Surgical, Lippincott Williams \& Wilkins, Thieme, Jaypee Publishing, and Slack Publishing; direct stock ownership in Avaz Surgical LLC and Vital 5 LLC; being a consultant for Zimmer Biomet and K2M; board membership in Vital 5 LLC, TDi LLC, and the Minimally Invasive Spine Study Group; 
editorial board membership in Contemporary Spine Surgery, Orthopedics Today, and Vertebral Columns; board of directors membership in CSRS, ISASS, and AAOS; and receiving a grant from the Cervical Spine Research Society.

\section{Author Contributions}

Conception and design: Singh, Parrish, Jenkins, Nolte, Massel, Myers. Acquisition of data: Singh, Parrish, Jenkins, Nolte, Hrynewycz, Brundage, Myers. Analysis and interpretation of data: Singh, Parrish, Jenkins, Myers. Drafting the article: Singh, Parrish, Jenkins, Nolte, Massel. Critically revising the article: Singh, Parrish, Jenkins, Nolte, Massel, Myers. Reviewed submitted version of manuscript: Singh, Parrish, Jenkins, Massel, Myers. Approved the final version of the manuscript on behalf of all authors: Singh. Statistical analysis: Parrish, Jenkins, Hrynewycz, Brundage. Administrative/technical/material support: Parrish, Jenkins. Study supervision: Singh, Parrish, Jenkins, Myers.

\section{Correspondence}

Kern Singh: Rush University Medical Center, Chicago, IL. kern. singh@rushortho.com. 